\title{
Nanocoatings on 2D Macroporous Silicon Structures
}

\author{
Liudmyla Karachevtseva1,2*, Mykola Kartel1,3, Bo Wang1, Oleg Lytvynenko',2, Yurii Sementsov ${ }^{1,3}$ \\ ${ }^{1}$ Ningbo University of Technology, Ningbo, China \\ ${ }^{2} \mathrm{~V}$. Lashkaryov Institute of Semiconductor Physics, NASU, Kyiv, Ukraine \\ ${ }^{3} \mathrm{O}$. Chuiko Institute of Surface Chemistry, NASU, Kyiv, Ukraine \\ Email: *lakar@kartel.kiev.ua
}

How to cite this paper: Karachevtseva, L. Kartel, M., Wang, B., Lytvynenko, O. and Sementsov, Y. (2019) Nanocoatings on 2D Macroporous Silicon Structures. Journal of Materials Science and Chemical Engineering, 7, 12-20.

https://doi.org/10.4236/msce.2019.77002

Received: March 4, 2019

Accepted: July 7, 2019

Published: July 10, 2019

\begin{abstract}
Macroporous silicon formed by photoanodic etching with high aspect ratio and large effective surface is one of the promising materials for the development of $2 \mathrm{D}$ photonic structures. We fabricated nanocoatings of $\mathrm{CdTe}, \mathrm{ZnO}$, CdS surface nanocrystals and $\mathrm{SiO}_{2}$ layers on macroporous silicon surface. The near-IR optical absorption was investigated and well-separated oscillations with giant amplitude were observed in the spectral ranges of surface level absorption. This process is because of resonance electron scattering on the surface impurity states with the difference between two resonance energies equal to the Wannier-Stark ladder. Macroporous silicon structures with $\mathrm{SiO}_{2}$ nanolayers and CdS nanocrystals are proposed to enhance the photoluminescence of CdS nanoparticles with quantum yield $28 \%$. Addition functionalization of $2 \mathrm{D}$ macroporous silicon is a result of the high-pressure oxidation. The structural $\mathrm{SiO}_{2}$ reorganization to orthorhombic phase increases the concentration of paramagnetic $\mathrm{P}_{\mathrm{b}}$ centers, EPR signal amplitude and GHz radiation absorption.
\end{abstract}

\section{Keywords}

Macroporous Silicon, Surface Nanocrystals, $\mathrm{SiO}_{2}$ Layers, Photoluminescence, High-Pressure Oxidation

\section{Introduction}

One of the promising materials for the development of $2 \mathrm{D}$ photonic structures is macroporous silicon formed by photoanodic etching with high aspect ratio and large effective surface [1] [2]. This determines optical and photo-physical characteristics of macroporous silicon structures [3] [4] [5] [6]. The existence of an 
intrinsic electric field $F_{S}=(5 \div 9) \cdot 10^{5} \mathrm{~V} / \mathrm{cm}$ is confirmed by electroreflectance study of macroporous silicon surfaces [7]. The near-IR optical absorption in 2D photonic macroporous silicon structures was investigated with allowance made for the linear electro-optical effect [8]. In this paper, the near-IR light absorption oscillations of 2D macroporous silicon structures with microporous silicon layers, CdTe surface nanocrystals and $\mathrm{SiO}_{2}$ nanocoatings are investigated taking into account the electro-optical effect within the strong electric field approximation. An analysis of the experimental absorption spectra is carried out within the model of the resonant electron scattering on impurity states in strong electric field, with difference between two resonant energies equal to the Wannier-Stark ladder.

\section{Materials and Method}

\subsection{ZnO Nanoparticles}

Methods of synthesis of $\mathrm{ZnO}$ nanoparticles in $i$-propanol and from solution of zinc compounds of $\mathrm{Zn}\left(\mathrm{CH}_{3} \mathrm{COO}\right)_{2}$ in ethanol have been developed. The average sizes of nanoparticles $\mathrm{ZnO}$ (3.7 - $4.4 \mathrm{~nm}$ ) were determined based on absorption spectra and atomic force microscopy [9]. ZnO nanoparticles deposited on a silicon substrate using ethanol introduce additional bands into the absorption spectrum $\mathrm{O}-\mathrm{H}$ bonds and ethanol-related organic compounds. The photoluminescence spectra of $\mathrm{ZnO}$ nanoparticles contain a narrow and low-intensity band of exciton photoluminescence and a much more intense band of "defective" photoluminescence with a maximum at $510-520 \mathrm{~nm}$ due to the recombination of an electron trapped by a deep trap. The increase in the size of the nanoparticles $\mathrm{ZnO}$ increases the intensity of the exciton photoluminescence by increasing the orderliness of the crystalline lattice of nanoparticles.

\subsection{CdS Nanoparticles}

The method of synthesis in aqueous and alcoholic solutions of polyethyleneimine of cadmium sulfide nanoparticles with an optimal concentration corresponding to the full saturation of the coordination sphere of $\mathrm{Cd}$ cations with amino groups was formed [10]. The average sizes of CdS $(1.8-2 \mathrm{~nm})$ were determined based on atomic force microscopy. X-ray diffraction spectra of CdS nanoparticles in polyethylenimine confirmed the crystalline structure of nanoparticles. For the CdS nanoparticles, a wide band of photoluminescence with a maximum of $2.45-2.65 \mathrm{eV}$ is measured, which at low temperatures increases and reaches the maximum possible efficiency of the radiative recombination-100\%. It is established that high efficiency of fluorescence of nanoparticles of CdS is associated with low probability of non-radiation recombination and low passivation of nanoparticle surface. Solid CdS films in polyethylenimine exhibited high photochemical stability under a strong and long-lasting irradiation with light at $\lambda=310-390 \mathrm{~nm}$ in the presence of air oxygen. The high quantum yield of photoluminescence of CdS solid films in polyethylenimine in combina- 
tion with high stability of films opens the prospects for their application in the production of light-emitting elements.

\subsection{Macroporous Silicon Structures}

The macroporous silicon samples to be studied were made of $n$-silicon wafers of [100] orientation (the electron concentration $n_{0}=10^{15} \mathrm{~cm}^{-3}$ ) using the photoelectrochemical etching [1]. Macroporous silicon structures (Figure 1) with macropore depth $h_{p}=70 \div 80 \mu \mathrm{m}$, diameter $D_{p}=2 \div 4 \mu \mathrm{m}$ and concentration $N_{p}=$ $(1.2 \div 1.9) \times 10^{6} \mathrm{~cm}^{-2}$ were etched. Colloidal solutions of $\mathrm{ZnO}$ or CdS nanocrystals were deposited onto the surface of macropores, and the sample was kept until complete evaporation of the solvent. The sample obtained was washed with distilled water to remove external salts. CdTe nanocrystals $20 \mathrm{~nm}$ in size were grown on the modified installation of metal dispersion using "a hot wall" [11] molecular epitaxy on macroporous silicon substrates. The undoped CdTe sputtered at a substrate temperature of $475 \mathrm{~K}$ and a source temperature of $650 \mathrm{~K}$ served as element of evaporation. The thickness of the deposited films $(200 \mathrm{~nm})$ was set by time of structure stay above the source of evaporation [12].

\subsection{Macroporous Silicon Oxidation}

$\mathrm{SiO}_{2}$ coatings on macroporous silicon structures were formed in diffusion stove in the nitrogen atmosphere [6]. The $5-200 \mathrm{~nm}$ thick oxide layers were formed on macroporous silicon samples in dry oxygen during 15 - $50 \mathrm{~min}$ at a temperature of $1050^{\circ} \mathrm{C}-1200^{\circ} \mathrm{C}$.

The $800-1200 \mathrm{~nm}$ oxide thick was formed at a temperature of $1100^{\circ} \mathrm{C}$ in wet oxygen using a steam generator with deionized water. The thickness of obtained $\mathrm{SiO}_{2}$ layers was determined from the time of structure staying above the source of evaporation. The oxide thickness was measured with accuracy of $0.2 \mathrm{~nm}$ using ellipsometry. $\mathrm{SiO}_{2}$ coatings on macroporous silicon structures were formed in diffusion stove in the nitrogen atmosphere [6]. The 5 - $200 \mathrm{~nm}$ thick oxide layers were formed on macroporous silicon samples in dry oxygen during 15 - $50 \mathrm{~min}$ at a temperature of $1050^{\circ} \mathrm{C}-1200^{\circ} \mathrm{C}$. The $800-1200 \mathrm{~nm}$ oxide was formed at a

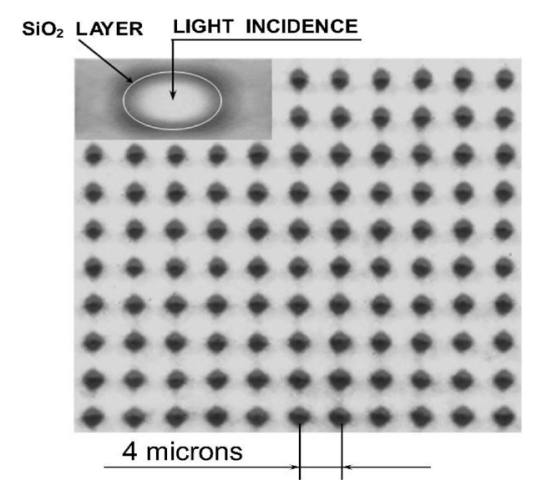

Figure 1. Macroporous silicon structure with periodic macropore distribution. Insert: $\mathrm{SiO}_{2}$ coating on macroporous silicon surface. 
temperature of $1100^{\circ} \mathrm{C}$ in wet oxygen using a steam generator with deionized water. The thickness of obtained $\mathrm{SiO}_{2}$ layers was determined from the time of structure staying above the source of evaporation. The oxide thickness was measured with accuracy of $0.2 \mathrm{~nm}$ using ellipsometry.

The chemical states on the surface of macroporous silicon structures with coatings and the electric field at the " $\mathrm{Si}-\mathrm{SiO}_{2}$ " boundary were identified by IR absorption using a PerkinElmer Spectrum BXII IR Fourier spectrometer. The optical absorption spectra are recorded at normal incidence of IR radiation on the sample (along the main axis of cylindrical macropores-see Figure 1, Insertion). The experiments are carried out at room temperature in the air. The error of spectral measurements is about $2 \mathrm{~cm}^{-1}$. The sensitivity of light intensity is $0.5 \%$. High-resolution X-ray diffractometry was used to measure residual deformations in the oxidized macroporous silicon matrix and the phase composition of $\mathrm{SiO}_{2}$ in the samples. The measurements were carried out using a high-resolution diffractometer "PANalytical X'Pert PRO MRD" in the $\mathrm{Cu}_{K \alpha}$ characteristic illumination [13]. The symmetric curves of (0004) reflection in $\mathrm{X}$-ray refraction were measured. This made it possible to determine the silicon lattice parameter $a$ along the normal to the structure surface and the value of residual strain $\Delta a$ in this direction. The voltage on the X-ray tube was $45 \mathrm{kV}$ and current was $40 \mathrm{~mA}$. The phase analysis was based on ICDD data. The values of residual deformations were obtained relative to the lattice parameter of the original silicon plate.

\section{Experimental Results}

\subsection{IR Light Absorption}

We investigated the near-IR light absorption oscillations in 2D macroporous silicon structures with CdTe (Figure 2(a) and Figure 2(b)), ZnO surface nanocrystals. Well-separated oscillations were observed in the spectral ranges of the surface bonds of macroporous silicon structures with surface nanocrystals (Figure 2(a)). The electro-optical effect was taken into account within the strong

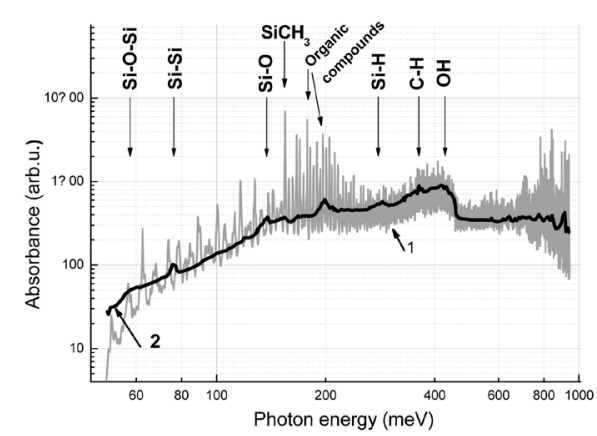

(a)

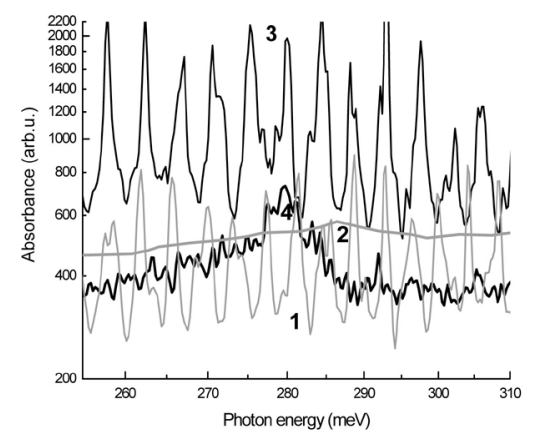

(b)

Figure 2. (a) Absorption spectra of macroporous silicon structures with CdTe surface nanocrystals (1) and without coatings (2); (b) Fragments of absorption spectra of macroporous silicon structures with CdTe surface nanocrystals (1), without coatings (2), with $\mathrm{ZnO}$ surface nanocrystals (3) in the vicinity of Si-H bonds. 
electric field approximation. The model of the resonant electron scattering on impurity states in electric field of heterojunction "silicon-nanocoating" on macropore surface as well as realization of Wannier-Stark effect on the randomly distributed surface bonds were considered. The Wannier-Stark ladders are not broken by impurities because of the longer scattering lifetime as compared with the period of electron oscillations in an external electric field, in all spectral regions considered for macroporous silicon structures with $\mathrm{CdTe}$ and $\mathrm{ZnO}$ surface nanocrystals.

\subsection{Enhancement of Photoluminescence}

Macroporous silicon structures with $\mathrm{SiO}_{2}$ nanolayers and $\mathrm{CdS}$ nanocrystals are proposed to enhance the photoluminescence of CdS nanoparticles due to reducing the electron recombination outside the nanoparticle layer. The deposition of a nanolayer of CdS on oxidized macroporous silicon structures (1) increases IR absorption in comparison with structures without a layer of CdS nanoparticles and (2) saves the mechanism of the electron scattering on ionized surface states. That increases the flow of electrons from the silicon matrix towards the CdS nanocrystal layer. The photoluminescence intensity depends on thickness of macroporous silicon layer (Figure 3(a)); the photoluminescence quantum yield depends electric field strength on boundary " $\mathrm{SiO}_{2}$-macropore surface" (Figure 3(b)).

The photoluminescence quantum yield of CdS nanoparticles on the surface of oxidized macroporous silicon with optimal thickness of $\mathrm{SiO}_{2}$ layer increases of $1.5 \div 2.3$ times during the first 2 weeks due to evaporation of water molecules from the nanoparticles in the polymer layer and reaches $28 \%$. With further storage of samples range and photoluminescence quantum yield almost no change [14].

\subsection{Oxidized Macroporous Silicon}

Functionalization of $2 \mathrm{D}$ macroporous silicon is confirmed for structures with

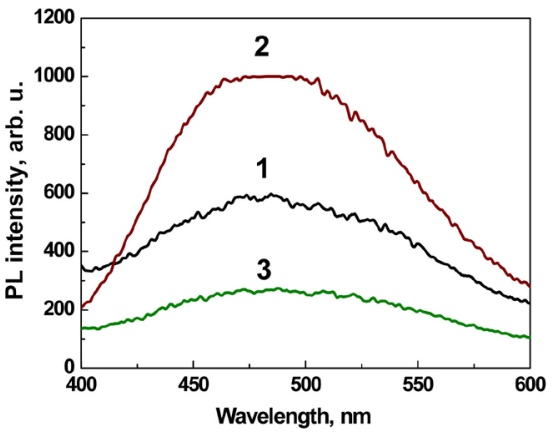

(a)

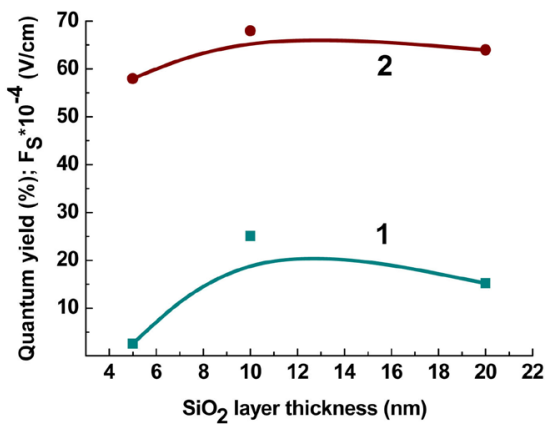

(b)

Figure 3. (a) The photoluminescence intensity vs thickness of macroporous silicon layer: 1 - 37 micron, 2 - 70 micron; 3 - 120 micron; (b) The photoluminescence quantum yield (1) and electric field strength on boundary " $\mathrm{SiO}_{2}$-macropore surface" (2) vs $\mathrm{SiO}_{2}$ layer thick. 
thick $\mathrm{SiO}_{2}$ layers [15]. High-resolution $\mathrm{X}$-ray diffractometry shows residual deformations in the oxidized macroporous silicon matrix and the phase composition of $\mathrm{SiO}_{2}$ in the samples.

Tetragonal $\mathrm{SiO}_{2}$ phase (cristobalite low) is formed in the oxidized single-crystal silicon (Figure 4). Data on oxidized macroporous silicon with thick $\mathrm{SiO}_{2}(800-1200 \mathrm{~nm})$ indicate the formation of $\beta$-tridymite $\mathrm{SiO}_{2}$ phase at distance between macropores 2 - 3 microns. Orthorhombic $\mathrm{SiO}_{2}$ phase ( $\beta$-cristobalite) was detected at distance between macropores 0.7 microns due to higher pressure in the silicon matrix with cylindrical symmetry of macropores and high thermal expansion coefficient of $\mathrm{SiO}_{2}$.

A polymorphic transformation of $\beta$-tridymite to $\beta$-cristobalite (orthorhombic $\mathrm{SiO}_{2}$ phase) occurs at the temperature $1470^{\circ} \mathrm{C}$. Silicon atoms form a lattice of diamond type in this highly symmetric modification to orthorhombic $\mathrm{SiO}_{2}$ at the lower temperature. Thus, the high-pressure regime is realized under condition of various thermal expansion coefficients of silicon $\left(2.6 \times 10^{-6}{ }^{\circ} \mathrm{C}^{-1}\right)$ and silicon dioxide $\left(5.6 \times 10^{-7}{ }^{\circ} \mathrm{C}^{-1}\right)$.

The structural $\mathrm{SiO}_{2}$ reorganization to orthorhombic phase in 2D macroporous silicon increases the concentration of paramagnetic $\mathrm{P}_{\mathrm{b}}$ centers (Figure 5(a)), EPR signal amplitude and $\mathrm{GHz}$ radiation absorption (Figure 5(b)). Addition functionalization of $2 \mathrm{D}$ macroporous silicon is direct result of the high-pressure oxidation. Thus, variation of the $\mathrm{SiO}_{2}$ layers thickness in oxidized macroporous silicon permits to change high-frequency signals. This is promising for development of filters and electronically controlled antennas.

\section{Conclusions}

Macroporous silicon formed by photoanodic etching with high aspect ratio and large effective surface is one of the promising materials for the development of $2 \mathrm{D}$ photonic structures. We fabricated nanocoatings of $\mathrm{CdTe}, \mathrm{ZnO}, \mathrm{CdS}$ surface nanocrystals and $\mathrm{SiO}_{2}$ layers on macroporous silicon surface.

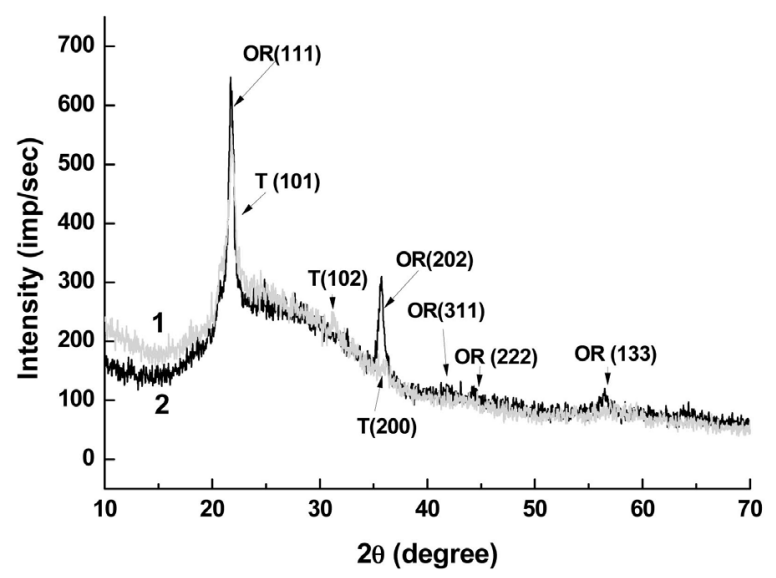

Figure 4. X-ray diffraction of oxidized macroporous silicon (curve 1) and oxidized single-crystal silicon (curve 2); $\mathrm{T}$-tetragonal $\mathrm{SiO}_{2}$ phase, OR-orthorhombic $\mathrm{SiO}_{2}$ phase, $\mathrm{SiO}_{2}$ thick is $800 \mathrm{~nm}$. 


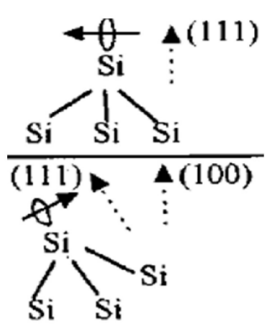

(a)

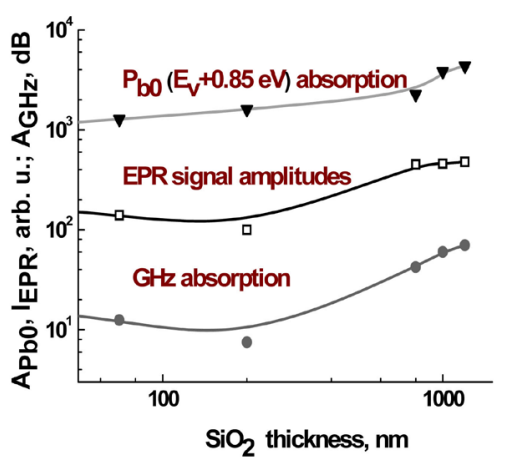

(b)

Figure 5. (a) $\mathrm{P}_{\mathrm{b} 1}$ centers-(111), $\mathrm{P}_{\mathrm{b} 0}$ centers-(100); (b) $\mathrm{P}_{\mathrm{b} 0}$ center absorption, EPR intensity and $\mathrm{GHz}$ radiation absorption vs the $\mathrm{SiO} 2$ thickness on macroporous silicon structures.

We evaluated the near-IR light absorption oscillations in macroporous silicon structures with $\mathrm{CdTe}, \mathrm{ZnO}$ surface nanocrystals. Well-separated oscillations were measured in the spectral ranges of the surface bonds of macroporous silicon structures with nanocoatings. The electro-optical effect was taken into account within the strong electric field approximation.

Macroporous silicon structures with $\mathrm{SiO}_{2}$ nanolayers and CdS nanocrystals are proposed to enhance the photoluminescence of CdS nanoparticles due to reducing the electron recombination outside the nanoparticle layer. The deposition of a nanolayer of CdS on oxidized macroporous silicon structures increased the flow of electrons from the silicon matrix towards the CdS nanocrystal layer. The photoluminescence quantum yield reaches $28 \%$.

Addition functionalization of oxidized macroporous silicon is a result of high-pressure conditions. The structural $\mathrm{SiO}_{2}$ reorganization to orthorhombic phase increases the concentration of paramagnetic $\mathrm{P}_{b}$ centers, EPR signal amplitude and $\mathrm{GHz}$ radiation absorption. Thus, variation of the $\mathrm{SiO}_{2}$ layers thickness in oxidized macroporous silicon permits to change high-frequency signals. This is promising for development of filters and electronically controlled antennas.

\section{Acknowledgements}

This work was supported by the Project of the Swedish Research Council (VR) under contract \#348-2014-4250 and by the Project of Scientific and Technical Cooperation between the National Academy of Sciences of Ukraine and the Ningbo University of Technology (China).

\section{Conflicts of Interest}

The authors declare no conflicts of interest regarding the publication of this paper.

\section{References}

[1] Birner, A., Wehrspohn, R.B., Gösele, U.M. and Busch, K. (2001) Silicon-Based 
Photonic Crystals. Advanced Materials, 13, 377-388. https://doi.org/10.1002/1521-4095(200103)13:6<377::AID-ADMA377>3.0.CO;2-X

[2] Karachevtseva, L.A. (2004) Two-Dimensional Photonic Crystals as Perspective Materials of Modern Nanoelectronics. Semiconductor Physics, Quantum Electronics \& Optoelectronics, 7, 430-435.

http://journal-spqeo.org.ua/users/pdf/n4_2004/v7n4-430-435.pdf

[3] Karachevtseva, L.A., Glushko, A.E., Ivanov, V.I., Lytvynenko, O.O., Onishchenko, V.F., Parshin, K.A. and O.J. Stronska (2007) Out-of-Plane Optical Transmittance of 2D Photonic Macroporous Silicon Structures. Semiconductor Physics, Quantum Electronics \& Optoelectronics, 10, 51-57. http://journal-spqeo.org.ua/n2_2007/v10n2-p051-057.pdf

[4] Glushko, A. and Karachevtseva, L. (2006) Photonic Band Structure in Oxidized Macroporous Silicon. Opto-Electronics Review, 14, 201-203. https://doi.org/10.2478/s11772-006-0026-9

[5] Glushko, A. and Karachevtseva, L. (2006) PBG Properties of Three-Component 2D Photonic Crystals. Photonics and Nanostructures, 4, 141-145. https://doi.org/10.1016/j.photonics.2006.02.003

[6] Karachevtseva, L.A., Karas', N.I., Onischenko, V.F. and Sizov, F.F. (2006) Surface Polaritons in 2D Macroporous Silicon Structures. Int. J. of Nanotechnology, 3, 76-88.

[7] Holiney, R.Yu., Matveeva, L.A., Venger, E.F., Litvinenko, O.A. and Karachevtseva L.A. (2001) Electroreflectance Study of Macroporous Silicon Structures. Applied Surface Science, 172, 214-219. https://doi.org/10.1016/S0169-4332(00)00861-8

[8] Karachevtseva, L.A., Ivanov, V.I., Lytvynenko, O.O., Parshin, K.A. and Stronska, O.J. (2008) Impurity Franz-Keldysh Effect in 2D Photonic Macroporous Silicon Structures. Applied Surface Science, 255, 3328-3331. https://doi.org/10.1016/j.apsusc.2008.09.038

[9] Karachevtseva, L.A., Kuchmii, S.Ya. and Lytvynenko, O.O. (2011) Oscillations of Light Absorption in 2D Macroporous Silicon Structures with Surface Nanocoatings. Applied Surface Science, 257, 3331-3335. https://doi.org/10.1016/j.apsusc.2010.11.016

[10] Raevskaya, A.E., Stroyuk, A.L. and Kuchmii, S.Ya. (2003) Optical Characteristics of Colloidal Nanoparticles of CdS Stabilized with Sodium Polyphosphate and Their Behavior during Pulse Photoexcitation. Theoretical and Experimental Chemistry, 39, 158-165. https://doi.org/10.1023/A:1024933023783

[11] Huber, W. and Lopez-Otero, A. (1979) The Electrical Properties of CdTe Films Grown by Hot Wall Epitaxy. Thin Solid Films, 58, 21-27.

https://doi.org/10.1016/0040-6090(79)90201-3

[12] Bilevych, Ye., Soshnikov, A., Darchuk, L., Apatskaya, M., Tsybrii, Z., Vuychik, V., Boka, V. and Sizov, F. (2005) Influence of Substrate Materials on the Properties of CdTe Thin Films Grown by Hot-Wall Epitaxy. Journal of Crystal Growth, 275, 1177-1181. https://doi.org/10.1016/j.jcrysgro.2004.11.207

[13] Karachevtseva, L., Kuchmiy, S., Stroyuk, O., Lytvynenko, O., Sapelnikova, O., Stronska, O., Wang, B. and Kartel, M. (2016) Light-Emitting Structures of CdS Nanocrystals in Oxidized Macroporous Silicon. Applied Surface Science, 388, 288-293. https://doi.org/10.1016/j.apsusc.2016.01.069

[14] Kladko, V.P., Kolomys, A.F., Slobodian, M.V., Strelchuk, V.V., Raycheva, V.G., Belyaev, A.E., Bukalov, S.S., Hardtdegen, H., Sydoruk, V.A., Klein, N. and Vitusevich, S.A. (2009) Internal Strains and Crystal Structure of the Layers in AlGaN/GaN He- 
terostructures Grown on a Sapphire Substrate. J. Appl. Phys., 105, Article ID: 063515. https://doi.org/10.1063/1.3094022

[15] Karachevtseva, L., Kartel, M., Kladko, V., Gudymenko, O., Wang, B., Bratus', V., Lytvynenko, O., Onyshchenko V. and Stronska, O. (2018) Functionalization of 2D Macroporous Silicon under the High-Pressure Oxidation. Applied Surface Science, 434, 142-147. https://doi.org/10.1016/j.apsusc.2017.10.029 